\title{
Writing for professional development: An introduction
}

\author{
Mireille Betrancourt and Giulia Ortoleva (Université de Genève, Switzerland), \\ and Stephen Billett (Griffith University, Australia)
}

\section{Writing and professional development}

Across human history, writing has been a central medium of knowledge constitution and dissemination. This was, firstly, as a prerogative for societal elites. Yet, overtime the mastery of writing and reading has become the basis of formal education far more broadly across populations. Now, it is the key vehicle for all levels of education: from primary school to university where it is used as both the means of progressing individuals' knowledge and also the means by which their learning is assessed. It stands as the key instrument by which what is known by human society is articulated and advanced, and, thus, through individuals engaging with others' writing and expressing what they know, believe and can do through their own writing, thereby advancing further what they know, can reproduce and utilize that knowledge. Hence, writing plays a considerable role in human development at the both social and individual levels (Schnotz, 2001). While learning and teaching writing skills has long been a topic in humanities, it is only in the second half of the 20th century that the relation between writing and learning becomes a matter of scientific investigation. The initial model advanced by Hayes and Flower (1980) paved the way for a lively trend of research on the cognitive processes involved in writing in relation with the writers' knowledge. Later, the research established that writing could also support the development of new knowledge, through reorganization and inference processes (Bereiter \& Scardamalia, 1987; Galbraith, 1999).

Schematically, two main lines of research associated with writing emerged in the last few decades. The first one examined the process of learning to write, particularly in secondary and higher education, and also in the context of foreign language acquisition (Ransdell \& Barbier, 2002). This line of inquiry investigated how writing is learnt to identify the developmental, cognitive and instructional aspects of writing and to understand how it can be taught and learnt in different contexts (Rijlaarsdam, Bergh \& Couzijn, 2005). The second line of inquiry is less interested in the writing processes per se than in the impact of writing activities (e.g. reflexive, argumentative, expository etc) on the development of new ideas, beliefs, and knowledge, both at individual or collective levels. A range of theories have been developed and a large body of research has been conducted to identify the conditions under which writing can be conducive to learning (Tynjälä, Mason \& Lonka, 2001). Far from being mutually exclusive, these two lines of inquiry in learning to write and writing to learn, are instead considered as offering complementary perspectives (e.g. see Jonassen \& Kim, 2009) for argumentative writing. Together, it seems that these two lines of inquiry can add much to the understanding of both the cognitive and procedural capacities through which writing is undertaken and can also be learnt.

However, whilst writing has received a great deal of attention across all educational levels, relatively few researchers have studied the impact and implications of this type of activity as a tool for professional development. This gap exists regardless of the fact that writing has become a key activity in the majority of workplaces. The key role of writing in the workplace has arisen because of changes in their organization: The growing use of technology to capture and distribute information together with the progressive reduction of some administrative support roles means that these tasks are no longer undertaken by specific support staffsuch as secretaries. Instead, workers with various roles and educational backgrounds are nowadays required to write more or less complex texts in 
their everyday work practice. It is, therefore, crucial to understand how writing is used in occupational practice both as skill with which to be competent and, given its extensive use in educational programs, as a tool for professional development. To address this gap, research needs to consider current writing practices at all levels, from students in vocational education to workers already engaged in their occupation. In this case, again, we believe that a dual perspective is very important approach to this inquiry. That is, to consider, on the one hand, the process of learning to write in and for work, following the standards and rules specific to each occupational field, as well as writing to acquire occupational knowledge.

The project for this volume is, therefore, to explore and illuminate how the task and process of writing can be used as a tool for professional development, both for the purposes of initial preparation for occupations and ongoing development within them. An inclusive approach to and conception of writing is adopted here in recognition of the different and quite particular ways that the process of writing can be used as a pedagogic tool to create new insights, develop further procedural capacities and support the construction of professional identity. This inclusiveness extends to approaches that are directed at fostering the acquisition of practice-related knowledge (i.e. procedural, conceptual and dispositional) of the kind required to develop occupational capacities on entry to an occupation and in its further development across working lives. To achieve that aim, this volume has gathered and presents contributions reporting research and scholarly activities from a range of fields of professional practices and a correspondingly wide range of education sectors. That is, the sites where occupations are practiced which require written work and where practitioners need and continue to learn across their working lives. In this way, considerations of developing and extending professional knowledge through writing are not just seen as being something arising as a product of engaging in educational programs, but also as a development practice that can occur within, but also outside of those programs. These considerations include a range of instructional practices and developmental strategies ranging from teacher interactions to engagement with technologies and interactions with others and to the relatively independent processes of writing.

In advancing these contributions to our understanding of the relations between writing and professional development, this volume comprises three sections that each representparticular perspectives on writing for professional development. The first section - Writing for professional development: Conceptions and purposes - introduces the theories and concepts associated to writing in the occupational context. The contributions here include a range of topics, from the mimetic processes enacted in writing, to the account of the multiple psychological processes underpinning the writing activity, and the importance of professional experience and how writing can support the process of engaging with it. The second section - Writing for learning professional practices presents research on activities in which writing was used explicitly to support the learning process. This approach was applied in a number of different contexts, and particularly studies in the health domain and teacher' education for instance,, and across a range of educational levels, from initial vocational training to higher education. Finally, the third section - Writing in practice - accounts for a series of contributions on how practitioners learn to write for their professional requirements and how their writing contributes to further fostering their expertise.

\section{Writing for professional development: Conception and purposes}

The first section of this edited volume offers accounts of the purposes of writing as a professional development activity and conceptions of what that activity might, can, and does progress, and its 
contributions to the ongoing learning of those who write. Explanatory accounts of how acts of writing can be generative of developing further professional capacities are also elaborated here. These explanatory accounts describe and exemplify how written forms can be used to secure the learning of practical, conceptual and procedural capacities, and also discuss the attributes and qualities of different instructional models. Hence, this section elaborates writing as a mediating tool to secure learning outcomes within educational programs and professional experiences.

In overview, in Chapter 2 - Learning through Writing: Mimetic Processes in action, Stephen Billett discusses the process of learning arising from engagement in the activities and interactions that comprising written tasks. More specifically, it proposes the idea that learning is a product of the mimetic processes that underpin human cognition and are central to thinking and acting, and therefore learning, when engaged in writing. In his chapter he outlines the nature, contribution and worth of learning through mimesis (i.e. observation, imitation and rehearsal), while also presenting ideas and theories advanced by other contributors to the volume within this purview. Following this contribution, Chapter 3 - Writing as a Body-Mind Performance Learning Activity for the Development of Professional Artistry in Learners -comprises an elaborated account of psychological processes that underpin activities such as writing, by largely drawing upon the body of work undertaken by its author, Ashgar Iran-Nejad. Specifically, in this chapter writing in described as a body-mind performance learning activity, integrating intellectual, affective, emotional, and behavioral understandings for the development of "professional artistry" in learners. In this way, it sets out an encompassing platform of premises for understanding the process of writing and, therefore, how it might be learnt and developed further in and for occupational purposes. Concluding this section, in Chapter 4 - How to Give Reality to Professional Experience through Writing -, Sabine Vanhulle and Anne Perréard Vité discuss the relevance and reality of professional development experiences and how these experiences can be engaged through writing. This research, conducted in the field of teachers' education, comprises a linguistic analysis of professional development portfolios. In doing so, it illuminates students' underlying concerns: value systems, motivations and intentions; as well as tensions amongst scientific knowledge and actual experience; and construction of conflicting identities in future teachers. The chapter describes in detail the instruments and methodology used to perform this analysis. The main claim of this study is that discourse analysis enlightens boundaries between reflective writing used to develop relevant valuations about professional situations and to regulate practices and between concepts and action rules.

In this way, this opening section sets out bases for considering how the practice of and learning of writing co-occur and can be understood as these dualities, and also the practical and pragmatic contexts in which writing is and can be used for the purposes of professional development. These premises include the importance of understanding not only the social and cultural context in which writing is used for professional development purposes, but also those who come to engage with writing for these purposes. Consequently, it is not sufficient to consider writing as professional development only in terms of strategies or approaches because it is also necessarily those who are to engage in professional development process and writing that need to be considered.

\section{Writing for learning professional practices}

The second section of the volume comprises a series of chapters drawing upon studies in which writing has been used to initially develop professional skills. The contributions comprise studies from a range of occupations and include inquiries that have adopted a range of methods, such as the use 
of reflective writing, collaborative writing and peer feedbacks, as well computer-supported instructional design.

The first six chapters discuss the use and contribution of reflective writing in various professional training contexts: teachers, bakers and cooks, commercial employees and health practitioners in different fields. In their Chapter 5, Luisa Alvares Pereira and her co-authors investigate how teachers (and teacher trainers) can be prompted to reflect about their experience of teaching to write through processes referred to as reflexive writing. In the project reported in this chapter, which is entitled - Writing to Learn from Experience and from Narratives Written about Experience - free reflective writing was used as a tool for reflective learning from the participants' experiences through narratives written about their teaching experiences. The authors hold that this process unveiled the complexities of learning from professional experience for teachers and teacher educators and how the practice and experiences intermingle in complex ways in the construction of extended professional meanings for the participants.

Reflective writing is also explored in Chapter 6, - Reflective Writing in a Learning Journal: Promoting the Use of Learning Strategies and supporting the Development of Professional Skills where Laetitia Mauroux and her co-authors present an account based on an empirical inquiry that analyses the use of reflective writing journals in the context of initial vocational education. The chapter examines the relevance of reflective writing as means to promote the use of learning strategies and to support the development of professional skills for bakery and cooking apprentices. The authors particularly highlight the importance of the use of prompts as a way to engage learners in the use of learning strategies, guiding their reflection. Hence, the structuring of the writing process is supported by means that seek to enrich it as a pedagogic tool for these learners. Moving to the analysis of writing in the healthcare domain, Chapter 7 - Students' Experience of Reflective Writing as a Tool for Learning in Physiotherapy - focuses on the analysis of reflective writing practices for learning professional skills in physiotherapy. Merja Kurunsaari along with her co-authors present and discuss a case where learners were confronted with reflective writing activities for learning and professional development purposes. Their analysis, based on self-appraisal of videos on their school lessons and clinical placement, revealed a variety of responses ranging from seeing writing as a useless task to regarding it as necessary for professional development. This chapter again points to the necessary structuring and support required for writing to be effective as a professional development tool.

The health care sector is also discussed in Linda Sweet and Pauline Glover's research on midwifery students, in Chapter 8. Their chapter - The Language of Midwifery - presents the use of reflective practice for professional development, and the acquisition of professional language: a key aspect of professional development. In particular, it demonstrates how the use of reflective writing enabled midwifery students to develop from descriptive to reflective writing over time and how these activities developed their capacity of professional language required within midwifery and when working with other healthcare sector workers. Reflective writing activities in the context of audiologist studies are analysed by Kirk Sullivan and Peter Czigler, in Chapter 9. In the analysis they report in this chapter entitled - Using Writing to Support Student Audiologists' Professional Development During Periods of Practical Training - the authors analyse the type of reflection that can be identified in audiologist students' reflective writing. Additionally, they consider whether the use of formative feedback on reflection can result in improved reflective writing pieces to be used for differential grading. The authors conclude that when such professional development processes are used in situations where assessment occurs, the outcomes may be constrained by these practices. 
From a different perspective, Elena Boldrini and Alberto Cattaneo in Chapter 10 analyse the use of reflective writing processes for the development of procedural capacities in the context of initial vocational training for commercial employees. Several interventions are presented in this chapter entitled - Individual and Collaborative Writing-to-Learn Activities in Vocational Education - in which the use of individual and collaborative writing activities are implemented, thereby highlighting how reflective writing can be part of both individual and collaborative scenarios, with the latter offering the opportunity for confrontation and sharing amongst peers. On this basis, the authors identified Instructional recommendations for the successful implementation of reflexive writing activities for professional development, thereby again emphasising the importance of structuring and supporting writing as a means of securing effective professional development experiences. To conclude this section, in Chapter 11 - Computer-Supported Collaborative Writing for Professional Development - Giulia Ortoleva and Mireille Bétrancourt analyse the impact of computer and technology on the practice of writing. This chapter presents an analysis of how technology can be used to enable, facilitate and support writing, and, particularly, collaborative writing, as a learning tool in vocational education and professional training. To illustrate the topic, the authors review two sets of studies involving two types of computer-supported collaborative writing activities for professional development, oriented respectively towards collaborative production and asynchronous discussions, in two different domains: teacher education and health care sector. Like other contributions to this section, these authors identify the importance of, albeit in different ways, the support and guidance for professional development through writing.

In all, the contributions across this section provide illustrations of some practices in which writing is used for initial professional learning purposes and also a range of strategies that have been utilised to achieve particular kinds of professional development outcomes. Most, but not all, of these purposes are associated with specific educational intents (i.e. those associated with particular occupations). The exception is one in which there is a more general focus on personal development. Yet, what seems common across most of these contributions is the importance of the organisation and structuring of writing experiences and the need for support and guidance to secure the kinds of professional development goals for which writing is being utilised.

\section{Writing in practice}

The third section of the volume comprises contributions on how practitioners learn to write in their professional practice and how that writing contributes to further foster their expertise. That is, ongoing professional development. Whilst the ability for specific writing practices is often one of the capacities required on entry to an occupation, it can also be used for ongoing development across working lives in response to changing work requirements and ways of working within occupations. In recent decades, there has been a great change in the level and type of writing skills required in workplaces, but how did educational provisions adapt to take these new requirements into account? This section, additionally, analyses practice that sits outside of what occurs within educational programs and institutions, namely teacher guidance and practice.

In Chapter 12 - Professional Text Genres: Writing Standards in Vocational Education - Astrid Neumann proposes that the expectations towards workers as writers are rapidly evolving and, consequently, professional writing is becoming an essential element of the ongoing education of workers. Her research presents three empirical studies to explore this topic, each one targeting the definition and presentation of writing in vocational education, either in terms of expectations of the companies, the curricula of the school, and the actual competence of learners entering this 
educational path. She identifies, through the presentation of the studies, a very clear gap between the high expectations of companies towards apprentices' competencies on the different levels of the German vocational training system, which, should be taken in serious consideration by policy makers. In this way, she notes the tension between expectations and what levels of writing are available within the workforce, thereby setting out the importance of the ongoing development of writing capacities for contemporary work.

On similar premises, in Chapter 13 - Learning to Write as a Professional: Engineers and Physiotherapists in Britain and Germany - Esther Breuer and her co-authors discuss how specific writing competencies are a key element in any professional skill-set. Professional education, however, often fails to address these competencies in a structured way. The research reported in this chapter describes and discusses the results of a survey analysing the importance of writing in professional education, exploring two professions: engineers and health professionals, in two different countries: Britain and Germany. The results suggest that the experiences and views on writing differ not only between national cultures, but also, within the professions, amongst different member groups: the students, the teachers, and the practitioners. Hence, again the social and cultural context within which writing occurs is not fixed and is subject to particular workplace expectations and cultural practices. In Chapter 14 - Learning to Write Simple Literature Reviews: A VET Student's Progress - Ann Kelly analyses an Australian programme aiming at assisting trainers in the teaching of writing. What emerges from this examination is that the guidance that is available within this material is minimal and not reflective of current research in the field of writing. The author provides a series of recommendations. These include the use of models of authentic workplace texts and the exploration of studies, within both the research areas of disciplinary literacy and systemic functional linguistics, to determine whether the insights and practices within this corpus could address the prevailing serious gap in professional development advice available to vocational education trainers.

Rebecca Woodard, in Chapter 15 - Discovering the Courage to Write: Teachers Recognizing the Affective Dimensions of Writing and Transforming their Classroom Instruction -, explores the emotional and affective dimensions involved in writing and teaching writing. The research describes the trajectories of three teachers involved in writing activities and how this type of activity impacts on their teaching of writing in the classroom. It concludes that teachers' experiences with writing transformed their classroom practices, enhancing their emotional participation, as they wrote alongside students and provided more opportunities for students to revise and share writing.

Two chapters then focus on the role of writing in the professional development of researchers and academics. In Chapter 16, Ray Smith - Developing Professional Practice through Writing: A Researcher Perspective - discusses his own experience in using writing to examine the work and learning practices of workers for the purpose of understanding better how people learn through work and the kind of support they need. Through illustrative examples of some of the conceptual foundations and findings from a specific project of the researcher's work, the chapter elaborates how writing has contributed to his professional development. The author advocates writing for professional development as an embracing of the knowns and unknowns that characterise the negotiations that constitute engagement in occupational practice. In Chapter 17 - Becoming an Academic: Reflective Writing and Professional Development - , Cecile Badenhorst and her co-authors, Rhonda Joy, Sharon Penney, Sarah Pickett, Jacqueline Hesson, Gabrielle Young, Heather McLeod, Dorothy Vaandering, and Xuemei Li discuss the experience of a writing group in the context of a faculty of educational sciences, in which new faculty members did not have much experience in the 
research field. These written reflections revealed crucial for learning the professional practices of being an academic. The data indicated that group members found that this method supported their professional development and enabled them to reflect on the shifting boundaries between personal/professional, work/home, and novice/expert. The weekly writing meeting also allowed members to explore emotions, not often voiced in academic spaces, through the security of collaborative writing process.

In the last chapter, 18, - Constructing a Professional Communication Identity through the Final Client Deliverable -, starting from different premises, Terri Grant, considers that the value of writing for learning professional practices is not questioned. But what is equally unequivocal is that the 'look' of writing: how texts are designed and transformed has changed. The hurrying developments in professional communication practices in a digital age present both challenges and opportunities for on-going professional development in academia and the workplace. In this study, she investigates the construction of professional communication identity through the qualitative discourse analysis of a report produced by a group of students for a class involving a scenario pedagogy, which aims at assisting students in their transition from the academy to the workplace.

In sum, what becomes apparent across this third section is that both institutional and personal factors need to be accounted for if writing is to be used as an effective means of professional development. The institutional factors provide the expectations, means and even specific interventions to achieve the kinds of professional development outcomes that are required. These factors include the demands of employers, the requirements of work, the conventions of writing research papers and dissertations and the demands of contemporary working life. However, within all of this are also the readiness, capacities, and interests of those who engage in writing as an act of professional development. That is, personal factors.

\section{Writing as professional development}

What is evident from this introductory chapter is that this volume presents a broad range of conceptions of writing, purposes for writing associated with learning and development, and appraisals of processes and strategies that have been implemented for both initial learning of occupations and their ongoing development across working life, albeit in the professions, the trades or associated occupations. Accordingly, and collectively, the chapters offer an overview across a range of theoretical perspectives, research methods and approaches, occupational domains as diverse as health care practitioners, teachers, bakers, engineers, as well as academics' work. The studies reported and discussed in the chapter encompass a number of educational and professional levels, as they address learners in vocational education, university students and staff, as well as professionals with different levels of experience in their practice. Hence, the contributions of this volume offer a unique opportunity to get a global overview of the state of the art on writing for professional development, across conceptual, methodological and professional perspectives, leading the way to new insights in terms of scientific investigation and instructional practices.

\section{References}

Bereiter, C., \& Scardamalia, M. (1987). The psychology of written composition. Hillsdale, NJ: Erlbaum. Galbraith, D. (1999). Writing as a Knowledge Constituting Process. In D. Galbraith and M. Torrance (Eds.) Knowing What to Write. Conceptual Process in Text Production (pp. 137-158), Amsterdam: Amsterdam University Press. 
Hayes, R.J., and L. S. Flower. (1980). Identifying the Organisation of Writing Process. In L.W. Gregg, and E.R. Steinberg (Eds.) Cognitive Process in Writing (pp. 3-30), Hillsdale, NJ: Erlbaum.

Jonassen, D. H., \& Kim, B. (2009). Arguing to learn and learning to argue: design justifications and guidelines. Educational Technology Research and Development, 58(4), 439-457.

Ransdell, S., Barbier, M.-L. (Eds.) (2002). New Directions for Research in L2 Writing. Studies in Writing, Vol. 11, New York, NY: Springer.

Rijlaarsdam, G., Bergh, H., Couzijn, M. (Eds.) (2005) Effective Learning and Teaching of Writing: A Handbook of Writing in Education, Studies in Writing, Vol. 14, New York, NY: Springer.

Schnotz W. (2001). Sign systems, technologies, and the acquisition of knowledge, In J.-F. Rouet, J. J. Levonen \& A. Biardeau (Eds). Multimedia learning: cognitive and instructional issues (pp. 930), London : Elsevier Science, .

Tynjälä, P., Mason, L., \& Lonka, K. (Eds.) (2001). Writing as a Learning Tool: Integrating Theory and Practice. Studies in Writing, Vol. 7, New York, NY: Springer. 